Proceedings

\title{
Inkjet 3D Printed Miniature Water Turbine Energy Harvester-Flow Meter for Distributed Measurement Systems ${ }^{\dagger}$
}

\author{
Krzysztof Adamski *, Jarosław Adamski, Jan A. Dziuban and Rafał Walczak \\ Wrocław University of Science and Technology, Wrocław, Poland; jarek3@vp.pl (J.A.); \\ jan.dziuban@pwr.edu.pl (J.A.D.); rafal.walczak@pwr.edu.pl (R.W.) \\ * Correspondence: Krzysztof.adamski@pwr.edu.pl; Tel.: +48-605-127-603 \\ + Presented at the Eurosensors 2017 Conference, Paris, France, 3-6 September 2017.
}

Published: 8 August 2017

\begin{abstract}
An energy harvester fabricated by inkjet 3D printing based on miniature water flow turbine with mechanical and electrical components necessary for electrical energy generation is shown. Turbine (outside diameter $25.4 \mathrm{~mm}\left(1^{\prime \prime}\right)$ and $14 \mathrm{~mm}$ length) is able to generate electric power of $4 \mathrm{~mW}$ for $14 \mathrm{~L} / \mathrm{min}$ of water flow and it gives $0.7 \mathrm{~V}$ for optimal load resistance $\left(\mathrm{R}_{\mathrm{L}}=55 \Omega\right)$. The harvester itself may be used as self-suppling water-flow, zero-energetic sensor in the distributed nets of water consumption measurement.
\end{abstract}

Keywords: energy harvester; water turbine; flow meter; distributed sensors; 3D printing; inkjet; energy generator; flow measure; sensors system; additive manufacturing

\section{Introduction}

Miniature sensors systems can be used in many aspects of our life, one of this part is water use and pollution control. An example of potential application of such system is distributed sensors network that can be used in control of irrigation of farmland. Proposed here method of power supplying a single sensor node is powering with miniature water turbine integrated with water disturbing system and generating power from floating water. Fabrication of such sensor node requires development of the miniature mechanical part and electrical part. Here we propose application of $3 \mathrm{D}$ printing as powerful tool for rapid fabrication of a miniature turbine mechanical components. It is well known that 3D printing is recognized as a technology that can change the word [1]. In our previous works we presented that 3D printing can be successfully used to develop microfluidics structures [2,3]. Collected 3D printing know-how enables us development of more complicated miniature devices as the water turbine. From our previous works we concluded that inkjet 3D printing technique enables fabrication of microfluidic channels with the smallest diameter of $200 \mu \mathrm{m}$ [2] and is also able to produce moving and complicated parts like beam in the microvalve [3].

The proposed here harvester is based on a concept of multiphase electrical rotating generator. Almost similar concept have been presented in positions [4,5] but our solution is based on the process of 3D printing of parts of the harvester. Dimensions of our harvester are: outside diameter $25.4 \mathrm{~mm}$ and $14 \mathrm{~mm}$ length. Thus the device is 8 time smaller that presented in [4] and tree times smaller in comparison to [5], but density of power generated by the harvester is almost at the same level. Harvester have also two times lower "starting" water flow, $1.4 \mathrm{~L} / \mathrm{min}$ in comparison to $3 \mathrm{~L} / \mathrm{min}$ from [4]. 


\section{Material and Methods}

The harvester (Figure 1) was designed to fit geometry and dimensions of typical $1 / 2$ " water pipes connectors. Printed parts of the harvester were designed in Invertor professional 2014 (Autodesk Inc., USA). The components were printed with Projet 3510 printer (3D System, USA) with Visijet M3 Crystal build material and Visijet S300 support wax-like material. The printing resolution was 750 dpi planar $(X-Y)$ with $16 \mu$ m layer thickness of the single printed layer.

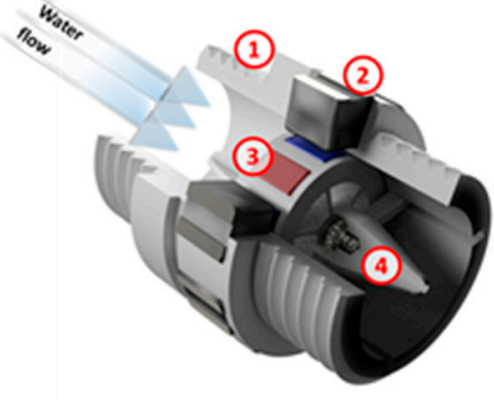

(1)

$1 / 2$ inch

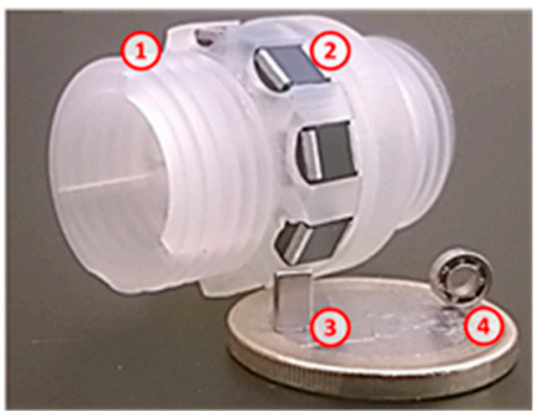

(3)

(4) conector inductor $47 \mathrm{pF}$

10 miniature Precision stainless ND magnet steel ball bering

Figure 1. 3D printed water miniature turbine: (a) visualized cross section view, (b) printed structure and other main components-neodymium magnets, coils and stainless steel bearing.

Electric part of the presented device contains nine small neodymium magnets $\left(1 \times 3 \times 5 \mathrm{~mm}^{3}\right.$, magnets.eu, Poland) and 9 SMD $10 \mathrm{mH}$ small $\left(5 \times 5 \times 4 \mathrm{~mm}^{3}\right)$ inductor coils (Viking NL20JT103, Taiwan). The magnets and coils are placed in respectively rotating turbine and stator housing in the specially printed (size and geometry) mounting holes. Outputs of each SMD inductor are connected with rectifiers (CS20D Graetz bridge, Diotec semiconductors, Germany) (Figure 2a). The generated power was collected from rectifiers in the capacitor $(4.7 \mathrm{uF})$ and managed by power management unit boost converter (BQ25504, Texas instruments, USA). The harvested energy was used for charging of a $3.7 \mathrm{~V}$ li-polymer battery.
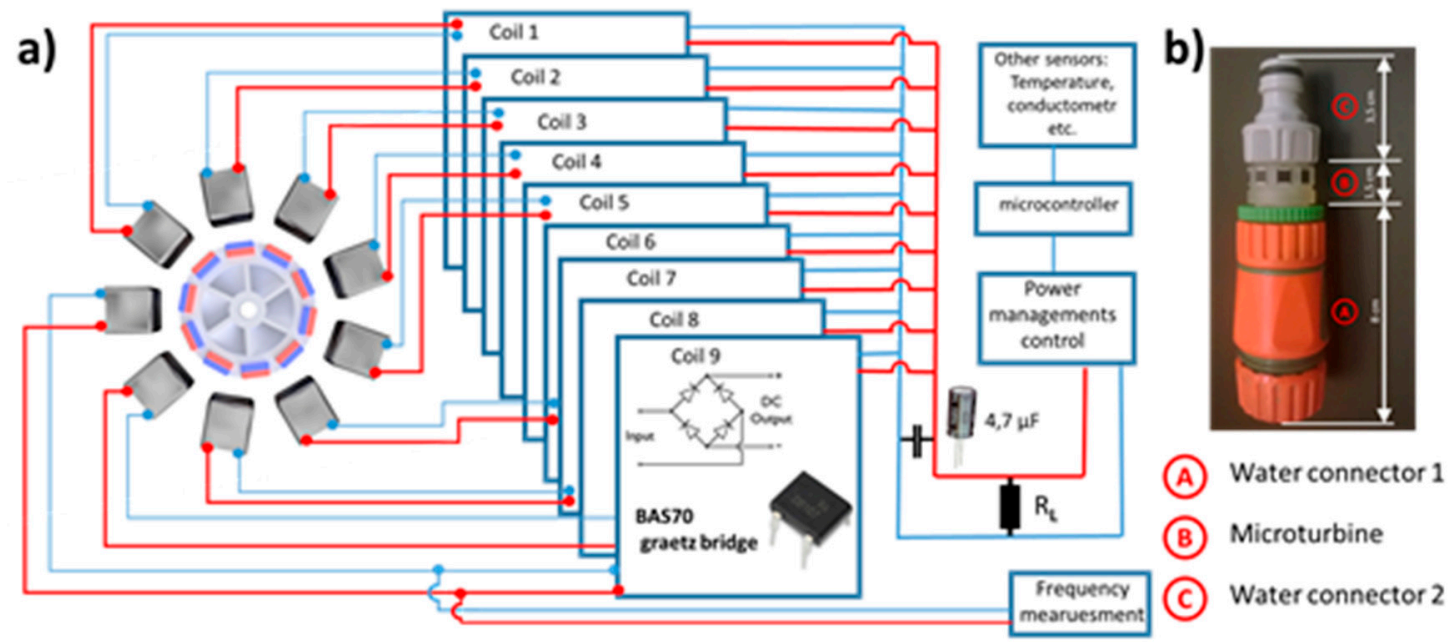

Figure 2. Miniature turbine energy harvester scheme (a) and view of the harvester as a part of garden water pipe (b). 
Small dimension of the turbine and 3D printing flexibility enabled integration of the energy harvester as a part of standard $1 / 2$ " water pipe connectors used commonly in home gardens (Figure 2b).

\section{Results}

Developed turbine-based energy harvester was electrically characterized (Figure 3). With maximal generating power of near $4 \mathrm{~mW}$ (Figure $4 \mathrm{~b}$ ) for $14 \mathrm{~L} / \mathrm{min}$ of water flow, turbine can be potentially used for charging battery and power supply of sensor system. Optimal resistance for proposed harvester was determined and it was $55 \mathrm{ohm}$ (Figure 4b). Power density was determined for optimal load resistance and calculated from Ohm's law.

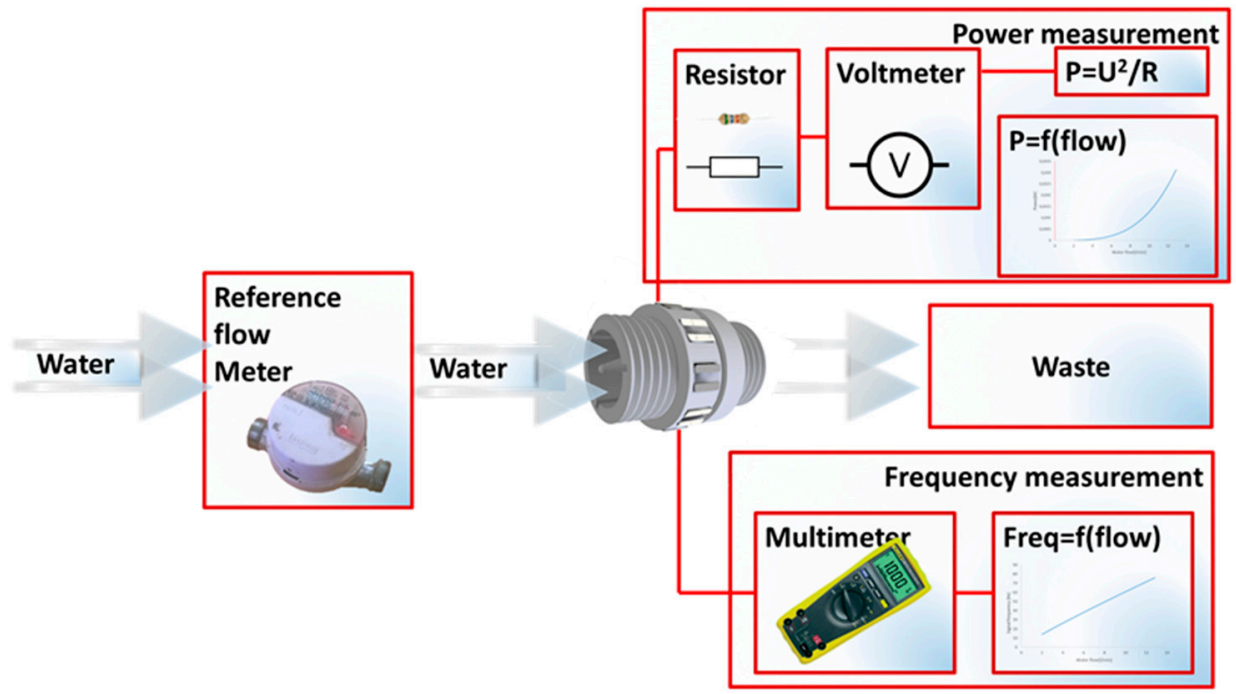

Figure 3. Characterization of water turbine with reference flow meter.

The turbine was also tested as flowmeter and characterized in reference to commercially available home water flowmeter. Obtained frequency charts were stable and reliable (Figure 4a). Starting flow of water at the moment when the turbine begins to rotate was $1.5 \mathrm{~L} / \mathrm{min}$. In case of 3phase power circuit (Figure $4 \mathrm{~d}-\mathrm{f}$ ) all output signals wave-form generated by the coils were properly observed. In that case more power was generated but higher starting flow was noticed.

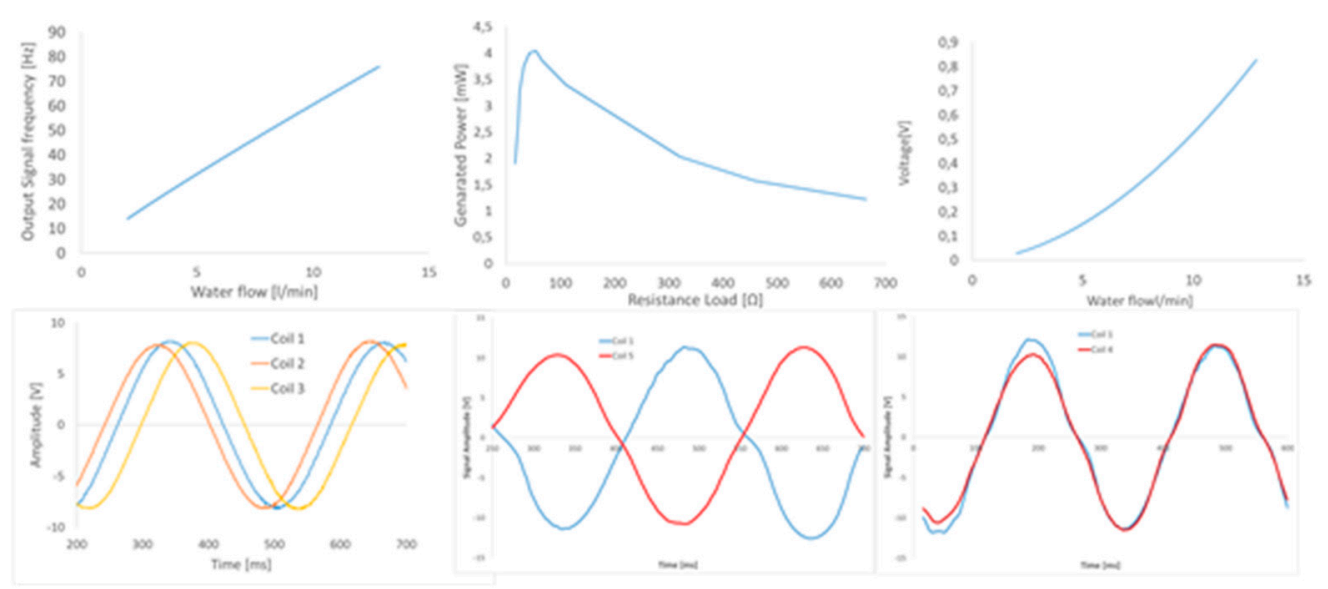

Figure 4. Electric characteristics of energy harvester: (a) frequency output signal as a function of water flow, (b) generated power function of loading resistance, (c) generated voltage function of water flow $(R L=55 \Omega)$, (d) output signal wave form for three inductors, (e) signal wave form for non in phase inductors, (f) signal wave form for in phase inductors. 


\section{Conclusions}

Power suppling of distributed network system for water control and consumption measure is a huge problem. Classical powering from on-grid network is very expensive and trouble full. One of the solution is generation of energy directly from water flow with rotating water turbine. Generated in this way power can be used for system powering and also it is possible to corelate frequency of generated electricity with water flow rate.

In this paper, design, system configuration and fabrication of 3D printed harvester (with embedded stainless steel bearings and electrical components) was presented. It was confirmed that inkjet 3D printing can be use as simple method for fabrication a complex self-powering, zeroenergetically. Results of energy harvesting were showed. On the base of obtained results characterising devolved energy harvester it is finally concluded that with probably additional optimisation of the mechanical and electrical construction the proposed energy harvester can be used for flow measurement and power supplying of low-power sensors (temperature, humidity, conductometer etc.) for water use and pollution recognition in the near future. Thus a first generation of $3 \mathrm{D}$ printed milimechatronic device is here shown for the first time.

Acknowledgments: The works are financed by Polish National Science Centre (NCN) under frame of the project no 2013/10/E/ST8/0342.

Conflicts of Interest: The authors declare no conflict of interest.

\section{References}

1. Waldbaur, A.; Rapp, H.; Länge, K.; Rapp, B.E. Let there be chip-Towards rapid prototyping of microfluidic devices: One-step manufacturing processes. Anal. Methods 2011, 3, 2681.

2. Walczak, R.; Adamski, K. Inkjet 3D printing of microfluidic structures-On the selection of the printer towards printing your own microfluidic chips. J. Micromech. Microeng. 2015, 28, doi:10.1088/09601317/25/8/085013.

3. Walczak, R.; Adamski, K.; Lizanets, D. Inkjet 3D printed check microvalve. J. Micromech. Microeng. 2017, 24, doi:10.1088/1361-6439/aa6152.

4. Boisseau, S.; Duret, A.-B.; Perez, M.; Jallas, E.; Jallas, E. Water flow energy harvesters for autonomous flowmeters. J. Phys.: Conf. Ser. 2016, 773, doi:10.1088/1742-6596/773/1/012019.

5. Hoffmann, D.; Willmann, A.; Göpfert, R.; Becker, P.; Folkmer, B.; Manoli, Y. Energy harvesting from fluid flow in water pipelines for smart metering applications. J. Phys.: Conf. Ser. 2013, 476, doi:10.1088/1742$6596 / 476 / 1 / 012104$.

(C) 2017 by the authors. Licensee MDPI, Basel, Switzerland. This article is an open access article distributed under the terms and conditions of the Creative Commons Attribution (CC BY) license (http://creativecommons.org/licenses/by/4.0/). 